Recibido: 24-04-2014

Aceptado: 20-08-2014

Palabras clave: unión civil no matrimonial, compañeros civiles, derechos y deberes.

Keywords: non-marital civil union, civilian peers, rights and duties.

María Teresa Cornejo Fava Abogada tcornejo6@gmail.com

\section{La unión civil: ¿necesidad de legislar en pro de minorías?}

\section{Civil union: need for regulation in pro minority?}

\section{María Teresa Cornejo Fava}

RESUMEN. Análisis de la necesidad y pertinencia de la propuesta de legislación que establece la unión civil no matrimonial para personas del mismo sexo. La propuesta legislativa de conformación de la unión civil no matrimonial para personas del mismo sexo suscita cuatro interrogantes fundamentales: 1. Como derechos fundamentales, sociales y económicos de la persona humana, la Constitución consagra el derecho de toda persona a la vida, a su identidad, a su integridad moral, psíquica y física y a su libre desarrollo y bienestar; a la igualdad ante la ley (declarando expresamente que nadie debe ser discriminado, entre otros, por motivo de sexo, de opinión o de cualquier otra índole); a la libertad de conciencia (no habiendo persecución por razón de ideas o creencias ni delito de opinión); a la intimidad personal y familiar; a la paz, tranquilidad, disfrute del tiempo libre, descanso y goce de un ambiente equilibrado y adecuado al desarrollo de su vida; a la legítima defensa; a la libertad y seguridad personales; a asociarse y a constituir fundaciones y diversas formas de organización jurídica sin fines de lucro, sin autorización previa y con arreglo a ley; a contratar con fines lícitos (siempre que no se contravengan leyes de orden público); a la propiedad y a la herencia; y a la familia: siendo ello así ¿es necesaria una ley que establezca la unión civil no matrimonial para personas del mismo sexo conformada "...con el fin de establecer y garantizar derechos y deberes, el uno para con el otro...”? 2. ¿Es necesario legislar en pro de minorías? 3. ¿Puede el derecho modificar la naturaleza de las cosas? 4 . ¿Es necesaria la referencia a la condición "no matrimonial" de la unión civil?

ABSTRACT. The legislative proposal to set up the non-marital civil union for same-sex people raises four key questions: 1 . As social and economic fundamental rights of the human person, the Constitution establishes the right of a person to life, an identity, moral, mental and physical integrity and to free development and welfare; to equality before the law (expressly declaring that no one should be discriminated against, inter alia, because of sex, opinion or any other); freedom of conscience (no persecution for having ideas or beliefs or crime of opinion); to personal and family privacy; peace, tranquility, leisure, relaxation and enjoyment of a balanced and developmentally appropriate environment for life; to selfdefense; to liberty and security of person; to organize and establish foundations and various forms of legal non-profit organization without prior authorization and in accordance with law; to hire for lawful purposes (provided that no laws contravene public order); to property and inheritance; and family: Then Does a law establishing non-marital civil union for same sex people formed is necessary "... to establish and safeguard rights and duties to each other ..."? 2. Is it necessary to legislate in favor of minorities? 3. Can the right change the nature of things? 4. does the reference to "non-marital" civil union status is required? 


\section{Antecedentes}

$\mathbf{E}$

1 Perú presencia el debate relativo a la conformación de la unión civil para personas del mismo sexo. Esta propuesta ha sido materia de sucesivos Proyectos de Ley, presentados y discutidos en el Congreso de la República.

El Proyecto de Ley 38142009-CR propuso la "Ley del Patrimonio Compartido", que en sus ocho (08) artículos regula el contrato de Patrimonio Compartido, consagrando una definición del mismo; las obligaciones, administración y disposición de dicho Patrimonio; las prohibiciones, requisitos y resolución del Contrato de este nombre; la liquidación del Patrimonio Compartido; y la supletoriedad de las normas del Código Civil.

En atención al Oficio No 582-2009-2010-CJDDHHR, de la Presidencia de la Comisión de Justicia y Derechos Humanos del Congreso de la República, ${ }^{(1)}$ y con su Oficio $\mathrm{N}^{\circ}$ 217-2010-JUS-AT, de fecha 25 de mayo de 2010, el Ministerio de Justicia remitió, con el correspondiente informe, la opinión que le fue solicitada con relación a este Proyecto, pronunciándose sobre la viabilidad del mismo, supeditada ella a la inclusión del articulado sugerido en los numerales 2 a 10 del referido Informe. (2)

El Proyecto de Ley 1481-2010-CR propuso una Ley que establece la unión civil entre personas del mismo sexo. ${ }^{(3)}$

El Proyecto de Ley No 4176-2010-CR recogió el texto que, en su Informe $\mathrm{N}^{\circ}$ 227-2010-JUS-AT, de 25 de mayo de $2010^{(4)}$ propuso el Ministerio de Justicia para esta Ley del Patrimonio Compartido. ${ }^{(5)}$

Como se indica en la respectiva Exposición de Motivos, los Proyectos de Ley $\mathrm{N}^{\circ}$ 0108-2011-CR ${ }^{(6)}$ y $\mathrm{N}^{\circ} 1393-2012-\mathrm{CR}^{(7)}$ recogieron el texto propuesto para

1 Congresista Víctor Rolando Sousa Huanambal

2 Informe $\mathrm{N}^{\circ}$ 227-2010-JUS-AT de 25 de mayo de 2010.

3 Como se indica en su Ficha de Seguimiento, este Proyecto de Ley 14812010-CR (31 folios) pasó al Archivo del Congreso con fecha 11 de noviembre de 2011 por fin del período parlamentario.

4 Remitido al Congreso de la República con el Oficio N² 217-2010-JUS-AT. 5 Teniendo como antecedente el Proyecto de Ley $N^{\circ} 3814-2009-C R$ y tal como se indica en su Ficha de Seguimiento este Proyecto de Ley 41762010-CR pasó al Archivo del Congreso con fecha 11 de noviembre de 2011 por fin del período parlamentario.

6 Teniendo como antecedentes los Proyectos de Ley $N^{\circ} 3814-2009-\mathrm{CR}$ y $\mathrm{N}^{\circ} 4176-2010-\mathrm{CR}$, este Proyecto fue retirado por su autor, el Congresista Carlos Bruce, el 22 de setiembre de 2011.

7 Que tiene como antecedentes los Proyectos de Ley N ${ }^{\circ} 3814-2009-\mathrm{CR}$,
Alétheia 2014, 2 (1)

la Ley del Patrimonio Compartido en el Informe $\mathrm{N}^{\circ}$ 227-2010-JUS-AT.

El Proyecto de Ley 2647-2013-CR propone ley que establece la unión civil no matrimonial para personas del mismo sexo. ${ }^{(8)}$

Constituye objeto del Proyecto de Ley $\mathrm{N}^{\circ}$ 2801/2013-CR la regulación de la "Atención Mutua" por acuerdo de voluntades entre dos personas, con la finalidad de establecer y reconocer derechos patrimoniales, sean estos de carácter pensionario o hereditario y otros. ${ }^{(9)}$

El Proyecto de Ley N 3273/2013-CR propone el Régimen de Sociedad Solidaria, entendiendo por ella “... el acuerdo voluntario entre dos personas mayores de edad que hacen vida en común con el objeto de asistirse, apoyarse y que origina derechos patrimoniales y otros que esta ley señala."(10)

De conformidad con lo dispuesto en el inciso b) del artículo $70^{\circ}$ del Reglamento del Congreso de la República y en su Pre Dictamen de marzo de 2014, la Comisión de Justicia y Derechos Humanos del

$\mathrm{N}^{\circ}$ 4176-2010-CR y Nº108-2011-CR.

8 Con Informe de fecha 24 de febrero de 2014, la Dirección General de Derechos Humanos del Ministerio de Justicia y Derechos Humanos hizo llegar al Titular del Sector el informe que contiene la opinión jurídico-técnica relativa al Proyecto de Ley $\mathrm{N}^{\circ}$ 2647-2013-CR que establece la unión civil no matrimonial para personas del mismo sexo, opinión que fue solicitada por la Presidencia de la Comisión de Justicia y Derechos Humanos del Congreso de la República mediante Oficio Nº80-CJ-DDHH-CR/2013-2014. En el respectivo informe, la opinión jurídico-técnica emitida señala, a modo de conclusión, que este Proyecto no solo resulta jurídicamente viable sino representativo de una concreción esencial de los derechos fundamentales al libre desarrollo de la personalidad y a la igualdad y no discriminación. Asimismo, con Oficio No 0128-2014-DP, de fecha 26 de marzo de 2014, la Defensoría del Pueblo remitió al Congreso de la República la opinión institucional contenida en el Informe de Adjuntía Nº03-2014-DP/ADHPD; en ella, se recomienda la aprobación del Proyecto de Ley $\mathrm{N}^{\circ}$ 2647-2013-CR que establece la unión civil no matrimonial para personas del mismo sexo. Dicha opinión sugirió, asimismo, evaluar las propuestas de modificaciones (que buscan fortalecer la propuesta legislativa señaladas en el mismo informe y relativas a la incorporación del procedimiento a seguir en caso de oposición a la inscripción de la unión civil no matrimonial, así como de algunas reglas respecto a la sociedad de gananciales; a los impedimentos para constituir una unión civil; a las causales para disolución de la unión civil; y a las modificaciones al Código Civil). Esta opinión institucional fue remitida, asimismo, por la Defensoría del Pueblo a la Presidencia de la Comisión de Justicia y Derechos Humanos del Congreso de la República (Oficio 0124-2014/DP del 26 de marzo de 2014) y a la Presidencia del Consejo Nacional de Derechos Humanos del Ministerio de Justicia y Derechos Humanos (Oficio 0125-2014/DP del 26 de marzo de 2014).

9 La atención mutua celebrada por dos personas no alterará el estado civil de las mismas y podrá contener derechos sucesorios y pensionarios así como el derecho a decidir para el inicio de tratamientos quirúrgicos de emergencia de uno de los acordantes.

10 La Sociedad Solidaria propuesta “... no altera el estado civil ni la relación de parentesco de sus integrantes...” 
140 UNIFÉ - EPG

Congreso de la República recomendó la aprobación de los Proyectos de Ley acumulados No 2647/2013CR, N ${ }^{\circ} 1393 / 2012-C R, N^{\circ} 2801 / 2013-C R$ y $N^{\circ}$ 3273/2013-CR, con el texto sustitutorio incluido en la parte final del referido documento. ${ }^{(1)}$

\section{Interrogantes fundamentales sugeridos por la propuesta de ley}

La propuesta de ley para la conformación de la unión civil no matrimonial para personas del mismo sexo sugiere cuatro interrogantes fundamentales: ¿Es necesaria una ley que establezca la unión civil no matrimonial para personas del mismo sexo conformada "...con el fin de establecer y garantizar derechos y deberes, el uno para con el otro..." siendo que la Constitución y la ley consagran, reconocen y garantizan los derechos fundamentales, sociales y económicos de la persona ${ }^{(12) ;}$ 2. ¿Es necesario legislar en pro de minorías? 3. ¿Puede el derecho modificar la naturaleza de las cosas? 4 . ¿Es necesaria la referencia a la condición "no matrimonial" de la unión civil.

La Constitución Política vigente en el país dedica su Título I a la persona y a la sociedad. Concretamente, bajo el enunciado de la defensa de la persona humana y del respeto de su dignidad como fin supremo de la sociedad y del Estado, los Capítulos I y II de este Título establecen los derechos fundamentales de la persona, y, asimismo, los derechos sociales y económicos de ella. ${ }^{(13)}$ Completando el otorgamiento de los derechos

11 Como se advierte de los correspondientes textos estos Proyectos proponen, respectivamente, las leyes de Unión Civil No Matrimonial para personas del mismo sexo; de Patrimonio Compartido, de Atención Mutua y del Régimen de Sociedad Solidaria.

12 Los derechos de toda persona a la vida, a su identidad, a su integridad moral, psíquica y física y a su libre desarrollo y bienestar; a la igualdad ante la ley (disponiendo expresamente que nadie debe ser discriminado, entre otros, por motivo de sexo, opinión o de cualquiera otra índole); a la libertad de conciencia (no habiendo persecución por razón de ideas o creencias ni delito de opinión); a la intimidad personal y familiar; a asociarse y a constituir fundaciones y diversas formas de organización jurídica sin fines de lucro, sin autorización previa y con arreglo a ley; a contratar con fines lícitos (siempre que no se contravengan leyes de orden público); y a la propiedad y a la herencia.

13 CONSTITUCION POLITICA DEL PERU 1993 - TITULO I - DE LA PERSONA Y DE LA SOCIEDAD - CAPITULO I - DERECHOS FUNDAMENTALES DE LA PERSONA. Artículo $1^{\circ}$.-La defensa de la persona humana y el respeto de su dignidad son el fin supremo de la sociedad y del Estado. Artículo 20.-Toda persona tiene derecho: numerales 1 a 24 (vida, identidad, integridad moral, psíquica y física, libre desarrollo y bienestar; igualdad ante la ley; libertad de conciencia y de religión, en fundamentales enunciados, el artículo $3^{\circ}$ del texto constitucional declara que la enumeración de los derechos establecidos en este Capítulo I “... no excluye los demás que la Constitución garantiza, ni otros de naturaleza análoga o que se fundan en la dignidad del hombre, o en los principios de soberanía del pueblo, del Estado democrático de derecho y de la forma republicana de gobierno." A mayor abundamiento, el Título Preliminar del Código Civil declara, en su artículo IX, que sus disposiciones se aplican supletoriamente a las relaciones y situaciones jurídicas reguladas por otras leyes, siempre que no sean incompatibles con su naturaleza.

Así, los derechos fundamentales, sociales y económicos de la persona tienen su concreción en el ordenamiento constitucional y legal vigente.

En efecto, los derechos que señalan los literales a, b y c del artículo $4^{\circ}$ de esta propuesta legislativa para los integrantes de la unión civil matrimonial (denominados en ella "compañeros civiles"), están ya consagrados, reconocidos y garantizados en las normas del ordenamiento peruano vigente relativas a la nacionalidad, a la libertad de asociación (con propósitos no lucrativos o con fines mercantiles), al derecho a la adquisición de bienes por acto intervivos a título oneroso

forma individual o asociada; libertades de información, opinión, expresión y difusión del pensamiento mediante la palabra oral o escrita o la imagen; solicitud sin expresión de causa la información que requiera y a recibirla de cualquier entidad pública; protección de la intimidad personal y familiar; honor y buena reputación; intimidad personal y familiar; voz e imagen propias; libertad de creación intelectual, artística, técnica y científica; propiedad sobre dichas creaciones y a su producto; inviolabilidad del domicilio; secreto e inviolabilidad de sus comunicaciones y documentos privados; elección de lugar de residencia; tránsito por el territorio nacional; reunión pacífica sin armas; asociación y constitución de fundaciones y de diversas formas de organización jurídica sin fines de lucro; contratación con fines lícitos y sin contravención de leyes de orden público; trabajo libre, con sujeción a ley; propiedad y herencia; participación, en forma individual o asociada, en la vida política, económica, social y cultural de la Nación; derechos de los ciudadanos de elección, de remoción o revocación de autoridades, de iniciativa legislativa y de referéndum; reserva sobre sus convicciones políticas, filosóficas, religiosas o de cualquiera otra índole; secreto profesional; identidad étnica y cultural; reconocimiento y protección, por el Estado, de la pluralidad étnica y cultural de la Nación; uso del propio idioma ante cualquier autoridad mediante un intérprete; formulación de peticiones, individual o colectivamente, por escrito ante la autoridad competente; nacionalidad; paz, tranquilidad, disfrute del tiempo libre y descanso, goce de un ambiente equilibrado y adecuado al desarrollo de su vida; legítima defensa; y libertad y seguridad personales. CAPITULO II DE LOS DERECHOS SOCIALES Y ECONOMICOS.- Artículo $4^{\circ}$. La comunidad y el Estado protegen especialmente al niño, al adolescente, a la madre y al anciano en situación de abandono. También protegen a la familia y promueven el matrimonio. Reconocen a estos últimos como institutos naturales y fundamentales de la sociedad. 
(compraventa) o a título gratuito (donación), al derecho a la adquisición de bienes mortis causa (esto es, a suceder a título universal, herencia, y/o a título particular, legado), a la propiedad; a la copropiedad (decisión sobre los bienes comunes y administración de los mismos por los copropietarios), a los derechos de uso y habitación, al parentesco, a los alimentos, a la sucesión testamentaria a título universal o a título particular, a las prestaciones de salud, de seguridad social y de vivienda, y a la protección contra actos de violencia personal y familiar.

En este orden de ideas, es pertinente señalar que no resulta necesaria una ley reguladora de la unión civil no matrimonial entre personas del mismo sexo: ello, en razón de que los derechos de la persona ${ }^{(14)}$ a que se refiere la propuesta de ley orientada a establecer la unión civil no matrimonial para personas del mismo sexo están ya establecidos, reconocidos y protegidos por el ordenamiento constitucional, legal y civil peruano.

El principio de generalidad que constituye característica esencial de la ley permite enunciar que ella comprende (sin excepciones de ninguna clase) a todas aquellas personas que se encuentran en las condiciones previstas por ella: así, la generalidad de la norma satisface el ideal de justicia de acuerdo con el que todas las personas son iguales ante la ley.

Esta igualdad de todas las personas ante la ley permite enunciar dos principios esenciales que, asimismo, regulan la tarea del legislador: el trato igual en los supuestos de hecho equivalentes y el tratamiento desigual que permite diferencias ante supuestos de hecho distintos. Como criterio básico para la producción normativa, el principio de igualdad ante la ley exige razonabilidad en la diferencia de tratamiento, consistente ella en el trato igual a los iguales así como en el trato desigual a los desiguales.

El enunciado de este principio y derecho fundamental a la igualdad ante la ley y de su necesario e ineludible correlato (en virtud del que ninguna persona puede ser discriminada por motivo alguno) conduce, como ineludible consecuencia, a establecer como innecesaria una legislación que norme la situación de las minorías cualquiera sea la naturaleza de estas.

14 Integrante de la unión civil no matrimonial que en la propuesta recibe la denominación de compañero civil
Constituye principio esencial del ordenamiento jurídico aquel que enuncia la necesidad de legislar en razón de la naturaleza de las cosas y no en razón de la diferencia de las personas. En este orden de ideas y en afirmación de Aristóteles al aplicar la ley, debe comprenderse y tenerse en cuenta la naturaleza de las cosas, de las situaciones.

La Constitución Política declara que la ley es igual para todos, sin discriminación alguna, pudiéndose dictar leyes especiales porque lo exige la naturaleza de las cosas, mas no por la diferencia de las personas. Este enunciado está recogido en el artículo $103^{\circ}$ del ordenamiento constitucional vigente. ${ }^{(15)}$

El derecho debe tener en consideración la realidad ontológica que busca regular aquella realidad sobre la que va a actuar; debe, asimismo, adaptarse tanto a los datos objetivos de la materia regulada como al orden metafísico de la naturaleza. Asimismo, el derecho (la ley) no puede ignorar estas realidades evidentes: si lo hiciera, deberá enfrentar dos riesgos, un resultado absurdo y una inoperancia del ordenamiento jurídico.

Un elemental reconocimiento de este principio conduce a enunciar que el derecho no puede modificar la naturaleza de las cosas.

Esta aseveración resulta estrictamente cierta y de particular relevancia tratándose de la familia y de una institución fundamental, origen y sustento de ella, el matrimonio.

La primera, fehaciente y más clara narración del origen del hombre en sus dimensiones individual y social y, asimismo, de la familia, se encuentra en el Génesis (acta de nacimiento del hombre) que, en sus primeros capítulos, se remonta a la primera y más antigua etapa de la raza humana, conformada por Adán y Eva.

Con su creación, el hombre fue traído de la nada; en este acto, el varón fue creado como ser individual, pleno y completo. No siendo bueno, sin embargo, que estuviera solo se le dotó de compañía necesaria y adecuada: en virtud del acto creador, el hombre descubre en la mujer un otro "yo" de su misma humanidad. (16)

15 Que consagra norma en virtud de la que "Pueden expedirse leyes especiales porque así lo exige la naturaleza de las cosas, pero no por razón de la diferencia de personas". Constituyen antecedente de esta disposición los artículos $187^{\circ} 23^{\circ}$ y $17^{\circ}$, respectivamente, de las Cartas de 1979; de 1933; y de 1920.

16 Génesis, 2, 18. 
142 UNIFÉ - EPG

Existe en el ser humano tendencia natural a unirse con persona de sexo opuesto para vivir con ella y para procrear prole que perpetúe su existencia sobre la tierra. Así, la familia tiene su origen en la unión de varón y mujer (dispuesta en el acto mismo de su creación), unión en la que -por esencia y naturaleza- consiste el matrimonio: esta realidad aparece, además, en los libros de Tobías y de Malaquías, ambos del Antiguo Testamento. ${ }^{(17)(18)(19)}$ (20)(21)(22)

17 Génesis, 1, 2, 18-24; 26-31.

18 Génesis, 1, 26 - 31. "Díjose entonces Dios: "Hagamos al hombre a nuestra imagen y a nuestra semejanza, para que domine sobre los peces del mar, sobre las aves del cielo, sobre los ganados y sobre todas las bestias de la tierra y sobre cuantos animales se mueven sobre ellas". "Y creó Dios al hombre a imagen suya, a Imagen de Dios lo creó, y los creó macho y hembra; y los bendijo Dios, diciéndoles: «Procread y multiplicaos, y henchid la tierra; sometedla y dominad sobre los peces del mar, sobre las aves del cielo y sobre los ganados y sobre todo cuanto vive y se mueve sobre la tierra». Dijo también Dios: «Ahí os doy cuantas hierbas de semilla hay sobre la haz de la tierra toda, y cuantos árboles producen fruto de simiente, para que todos os sirvan de alimento. También a todos los animales de la tierra, y a todas las aves del cielo, y a todos los vivientes que sobre la tierra están y se mueven les doy para comida cuanto de verde hierba la tierra produce». Y así fue. Y vio Dios ser muy bueno cuanto había hecho, y hubo tarde y mañana, día sexto."

19 Génesis, 218 - 24. "Y se dijo Yahvé Dios: «No es bueno que el hombre esté solo, voy a hacerle una ayuda proporcionada a él». Y Yahvé Dios trajo ante el hombre todos cuantos animales del campo y cuantas aves del cielo formó de la tierra, para que viese cómo los llamaría, y fuese el nombre de todos los vivientes el que él les diera. Y dio el hombre nombre a todos los ganados, y a todas las aves del cielo, y a todas las bestias del campo; pero entre todos ellos no había para el hombre ayuda semejante a él. Hizo, pues, Yahvé Dios caer sobre el hombre un profundo sopor; y dormido, tomó una de sus costillas, cerrando en su lugar con carne, y de la costilla que del hombre tomara, formó Yahvé Dios a la mujer, y se la presentó al hombre. El hombre exclamó: «Esto sí que es ya hueso de mis huesos y carne de mi carne. Esta se llamará varona, porque del varón ha sido tomada. Por eso dejará el hombre a su padre y a su madre; y se adherirá a su mujer; y vendrán a ser los dos una sola carne».

20 La institución del matrimonio dispuesta por Dios Padre \{cuyo establecimiento se narra de manera tan clara y precisa en el Génesis\} fue ratificada en su origen, naturaleza y concepto por Dios Hijo cuando - refiriéndose a la unión de hombre y mujer en que por esencia consiste aquél- dijo durante los tres años de su vida pública: «De manera que ya no son dos sino una sola carne» y «Lo que Dios ha unido no lo separe el hombre»." La unión de hombre y mujer en que indudablemente consiste el matrimonio fue dispuesta por Dios; más aún: como se aprecia del texto bíblico, Dios formó a la mujer de la costilla del varón que había creado, en razón de no ser bueno que el hombre esté solo; seguidamente, ordenó su unión indisoluble viniendo a ser los dos «una sola carne». (San Mateo, 19, 6, citado en el "Catecismo de la Iglesia Católica", número 1605).

21 Con el transcurso del tiempo esta unión de varón y mujer ha venido a ser conocida bajo la denominación de "matrimonio», vocablo que etimológicamente proviene de las voces latinas «matris» $\mathrm{y}$ «munium» que, unidas, significan «oficio de la madre» o más propiamente "carga de la madre» porque es ella la que lleva el peso mayor antes del parto, en el parto y después del parto, así como el «oficio del padre» es -o era- el sostenimiento económico de la familia. Ossorio, Manuel. Diccionario de Ciencias Jurídicas, Políticas y Sociales. Editorial Heliasta S.R.L., Buenos Aires Argentina. 1987. p. 452.

22 La realidad de Dios como autor del matrimonio aparece también en otros libros del Antiguo Testamento. Así, en el libro de Tobías - concretamente en la oración de Tobías hijo en la cámara nupcial - éste expresa ala-
Como se advierte de la narración del Génesis, la aparición de la primera criatura femenina hace evidente que la atracción de los sexos ha sido dispuesta como base del amor conyugal. La alteridad sexual del ser humano «varón y mujen» y la consiguiente reproducción sexuada no constituyen un simple hecho fortuito del proceso biológico terrestre, ni una dualidad de funciones, culturalmente formada: se trata de un designio originario, impreso como tal en la naturaleza humana.

Asimismo, el matrimonio y la familia no son instituciones puramente histórico-culturales, susceptibles ni de "superación" ni de regulación normativa según el arbitrio humano.

La familia, institución natural que se forma por la unión y la vida en común de varón, mujer y sus descendientes ${ }^{(23)}$ e institución básica de la sociedad, “... no es una creación del Derecho ni de la ley, que solo la regulan, sino obra de la naturaleza humana; y se dirige a satisfacer necesidades y exigencias inherentes a la persona como ser individual y social. No lo es por su estructura, ni por su funcionamiento, que responde, además, a exigencias y dinámicas metajurídicas" (24)

La familia existe de hecho. Sin embargo, el derecho busca darle especial protección a través de normas jurídicas que garanticen el cumplimiento mínimo de los derechos y obligaciones de los familiares entre sí: con este fin establece ciertas normas que, manteniendo su naturaleza, le dan inicio y término formal. Así, como fenómeno natural la familia tiene su origen en la unión de los sexos; como institución jurídica, su origen reside en la unión de los sexos sancionada por la ley (esto es, en el matrimonio).

Es pertinente recordar que la unión de los sexos constituye fenómeno natural dispuesto en el ser humano en el momento de su creación y que, por

banza y gratitud a Dios; recuerda los motivos y los hechos que justifican la petición de ayuda: «Tu creaste a Adán y para él creaste a Eva, su mujer, para sostén y ayuda, y para que de ambos proviniera la raza de los hombres. Tú mismo dijiste: No es bueno que el hombre se halle solo; hagámosle una ayuda semejante a él. (v.6).». En el Libro de Malaquías (en particular 2,15) se recuerda también la creación de la primera pareja como fundamento de la institución matrimonial y de sus propiedades.

23 Este es el núcleo de la familia al que puede añadirse los ascendientes y descendientes, los parientes colaterales y los parientes por afinidad. 24 Cornejo Chávez, Héctor - Derecho Familiar Peruano. Tomo I. Sociedad Conyugal. p. 11. Citado por Arias Schreiber, Max. Exegésis del Código Civil Peruano de 1984. Tomo VII. Derecho de Familia. Sociedad Conyugal. Gaceta Jurídica Editores. Agosto 1997 p. 11. 
tanto, ella es anterior y superior al Derecho que busca regularla.

De otrolado, el matrimonio no es asunto privado de los seres humanos: se trata de una institución que constituye el mejor ambiente en que una persona debe desarrollarse en su vocación propia de ser social (para encontrarse a sí misma y a los demás) de modo natural y casi espontáneo; de una institución insustituible, por su naturaleza y fines. Es una institución propia del hombre que proviene de la razón natural y que, por consiguiente, es racional: precisamente por serlo constituye entidad natural. Se trata de una entidad que nace en virtud de la ley natural inserta en el hombre desde siempre. ${ }^{25}$ )

Así, desde este punto de vista y sin duda alguna, el orden jurídico debe normar, regular, sancionar el fenómeno natural de la unión de los sexos conservando su naturaleza propia y resaltando sus caracteres inherentes sin modificarlos, sin alterarlos.

En consideración al origen de la familia como fenómeno natural (unión de los sexos) y como institución jurídica (unión de los sexos sancionada por la ley) es indudable que el orden jurídico debe normar tal fenómeno natural, conservando su naturaleza propia, resaltando sus caracteres inherentes (sin alterarlos ni modificarlos), y promoviendo esta institución natural a través de las normas reguladoras de la celebración y de la existencia del matrimonio.

Siguiendo a la naturaleza y a la realidad, la institución del matrimonio es el modo por el que la familia se constituye frente al derecho. En este orden de ideas, el ordenamiento constitucional vigente

25 Ello significa fundamentalmente que la unión entre varón y mujer procede de una inclinación de la voluntad imperada y regulada por un acto de la razón, «inclinatio rationalis» [no de las fuerzas instintivas, «instinctus naturae»] y que ella proviene del amor de dilección entendido como amor específicamente humano, movimiento de la voluntad regulado y medido por la razón, primaria y más fundamental inclinación de la voluntad hacia un bien. En suma, una realidad racional. Siendo que el matrimonio constituye expresión misma de la racionalidad del hombre así como ley e institución de derecho natural, cabe referirse a él como estructura jurídica que encuentra su motor en la inclinación racional y cuya norma es la razón. Conviene recordar que la ley es propia de la razón e inherente a ella y que, en tal virtud, es propia de los seres dotados de inteligencia y libertad \{pues sin albedrío solamente hay fuerza: los seres no inteligentes, irracionales se gobiernan y son movidos por fuerzas e instintos más no por leyes en sentido propio: cuando, impropiamente, se denomina leyes a tales fuerzas e instintos se lo hace en sentido analógico\}. consagra la protección de la familia y la promoción del matrimonio, ${ }^{(26)}$ por la sociedad y por el Estado. Es la legislación civil la que regula ambas instituciones naturales: lo hace con la finalidad de contribuir a la consolidación y fortalecimiento de la familia y en armonía con los principios y normas proclamados en la Constitución Política. (27)(28)

En efecto, mediante su norma suprema (la Constitución), el ordenamiento legal peruano sostiene la promoción del matrimonio.

Es indudable que la relación que da origen al matrimonio es una relación heterosexual.

El primer párrafo del artículo $4^{\circ}$ de la Constitución ( ${ }^{29}$ ) permite señalar que el matrimonio es la institución en base a la que (mediante la procreación de los hijos) se constituye la familia. Así, pues, conjuntamente con la vida común de los cónyuges, la procreación de los hijos (y su educación) constituye fin del matrimonio: esta vida común cobra sentido y plenitud con la descendencia que varón y mujer traen al mundo.

Al fijar el concepto de esta institución, el artículo $234^{\circ}$ del Código Civil se refiere a la vida común como fin para el que un varón y una mujer legalmente aptos para ella concertan voluntariamente una unión y la formalizan con sujeción a sus disposiciones.

Los artículos $287^{\circ}, 288^{\circ}$ y $289^{\circ}$ complementan tal norma al establecer (como propósitos y deberes recíprocos de varón y mujer unidos en matrimonio) la fidelidad, la asistencia, la vida común en el domicilio

26 En razón de su naturaleza de institución de origen de aquella 27 Código Civil.- Artículo 233․- Regulación de la familia.- La regulación jurídica de la familia tiene por finalidad contribuir a su consolidación y fortalecimiento, en armonía con los principios y normas proclamados en la Constitución Política del Perú.

28 Desde 1936 a la fecha, el matrimonio \{que el ordenamiento legal peruano denomina "civil" $\}$ ha sido y es el único capaz de producir efectos jurídicos, el único apto para conformar una familia para el derecho. La familia se constituye principalmente por el matrimonio y/o por el parentesco establecido y reconocido por la ley: en este sentido, Enrique Bernales Ballesteros afirma que el matrimonio es la forma de constitución de la familia frente al Derecho. \{Josserand, Louis. Derecho Civil. Tomo I, Volumen 2. Ediciones Jurídicas Europa-América Bosch y Cía. Editores. Buenos Aires, 1951, p.14, citado por Bernales Ballesteros, Enrique. La Constitución de 1993. Análisis Comparado. p. 161.\}

29 Que -valga la redundancia- instituye a la familia y al matrimonio como institutos naturales y fundamentales de la sociedad y que dispone la protección de la primera y la promoción del segundo por la comunidad y el Estado. 


\section{UNIFÉ - EPG}

conyugal y la alimentación y educación de los hijos. En consecuencia, son dos los fines del matrimonio: la vida común de los cónyuges y, como obligación recíproca de este varón y esta mujer, la procreación y educación de los hijos. ${ }^{(30)}$

El derecho debe reconocer y respetar la realidad ontológica que pretende normar.

En este orden de ideas y como necesaria y elemental consecuencia del principio en virtud del que resulta que el derecho no puede modificar la naturaleza de las cosas, el ordenamiento jurídico peruano ha conceptuado al matrimonio ${ }^{(31)}$ como la unión voluntariamente concertada por un varón y una mujer legalmente aptos para ella y formalizada con sujeción a las disposiciones del Código Civil, a fin de hacer vida común. ${ }^{(32)}$

En relación a la cuarta cuestión interrogante suscitada por la propuesta legislativa( $\left.{ }^{33}\right)$, se aprecia del texto de ella, de su Exposición de Motivos, de los Informes de la Dirección General de Derechos Humanos del Ministerio de Justicia y Derechos Humanos y de la Defensoría del Pueblo que la unión cuyo establecimiento propone ella es denominada "Unión Civil No Matrimonial."((34)

30 "Por el matrimonio el hombre y la mujer, asociados en una perdurable unidad de vida sancionada por la ley, se completan recíprocamente, y cumpliendo los fines de la especie la perpetúan al traer a la vida la inmediata descendencia": Concepto de Emilio Valverde. Cita de Cornejo Fava, María Teresa. Matrimonio y Familia: su tratamiento en el derecho. Ediciones Tercer Milenio. 2000. página 504.

31 Reconocido constitucionalmente como instituto natural y fundamental de la sociedad

32 Constituyendo primer deber recíproco del varón y la mujer así unidos el sostenimiento, protección, educación y formación de sus hijos, hecho que presupone su procreación como fin esencial de su unión matrimonial.

33 Que establece la unión civil no matrimonial para personas del mismo sexo

34 Es pertinente resaltar la declaración contenida en el primer párrafo de su artículo $1^{\circ}$ en el sentido que "A los efectos de la Ley, se entiende por Unión Civil No Matrimonial, a la unión voluntaria conformada por dos personas del mismo sexo con el fin de establecer y garantizar derechos y deberes, el uno para con el otro, dispuestos en la presente Ley." La Exposición de Motivos de esta propuesta legislativa señala de modo expreso que "Las uniones civiles tampoco devalúan la institución del matrimonio, pues esto implicaría que el Estado emite un juicio de valor y considera a las parejas homosexuales como inferiores. Aparte, no se está proponiendo ampliar el matrimonio a personas del mismo sexo, sino establecer una figura distinta (uniones civiles). Por último, bajo esta propuesta las uniones civiles sólo estarían disponibles a parejas del mismo sexo, no a heterosexuales, para los cuales el matrimonio civil y la unión de hecho seguirían siendo las únicas opciones."
La referencia a la condición "no matrimonial" de la unión civil que contiene el Proyecto de Ley $\mathrm{N}^{\mathrm{o}}$ 2647/2013-CR es innecesaria.

El matrimonio es, por naturaleza, esencia y definición, unión voluntariamente concertada "por un varón y una mujer". (35)

Como quiera que del texto de la propuesta legislativa y de su Exposición de Motivos resulta que esta unión está conformada por "personas del mismo sexo", de ello deriva una realidad evidente e indudable: la naturaleza no matrimonial de la unión civil.

Al denominar "Unión Civil No Matrimonial" a la unión que establece, el Proyecto de Ley $\mathrm{N}^{\mathrm{o}}$ 2647/2013-CR ha incurrido en una suerte de figura retórica consistente en la adición de palabras no necesarias en una frase pues su significado ya está incluido en ella, de modo explícito o implícito.

En efecto, la naturaleza (no matrimonial) de esta unión resulta evidente de su descripción como unión conformada en forma voluntaria por personas del mismo sexo.

Puede calificarse de redundancia el empleo de la expresión "no matrimonial" en la denominación de la figura jurídica constituida por el Proyecto de Ley $\mathrm{N}^{\mathrm{o}}$ 2647/2013-CR.(36)

35 Código Civil de 1984.- Artículo 234º- Noción del matrimonio.- El matrimonio es la unión voluntariamente concertada por un varón y una mujer legalmente aptos para ella y formalizada con sujeción a las disposiciones de este Código, a fin de hacer vida común. - Código Civil de 1852 . Artículo $132^{\circ}$. Por el matrimonio se unen perpetuamente el hombre y la mujer en una sociedad legítima, para hacer vida común, concurriendo a la conservación de la vida humana.

36 El texto sustitutorio del Predictamen de la Comisión de Justicia y Derechos Humanos del Congreso de la República \{recaído en los Proyectos de Ley No 2647/2013-CR, Nº 1393/2012-CR, N ${ }^{\circ}$ 2801/2013-CR y $\mathrm{N}^{\circ} 3273 / 2013-\mathrm{CR}$ \} dispone en su artículo $1^{\circ}$ que "Mediante la unión civil se establecen las situaciones y relaciones jurídicas originadas por la unión de dos personas del mismo sexo", suprimiendo el empleo de la expresión "No Matrimonial" que aparece del texto original de la propuesta legislativa. 